\title{
Research on Hazardous Characteristics for Complete Discharged Li-Ion Traction Batteries
}

\author{
Ying-hao XIE ${ }^{1 *}$, Hai-jun $\mathrm{YU}^{1,2,3}$, Yan-nan $\mathrm{OU}^{1}$, Jian-xiao $\mathrm{TANG}^{1}$, Bao-sen \\ WANG $^{2}$ and Chang-dong $\mathrm{LI}^{1,2}$ \\ ${ }^{1}$ Guangdong Brunp Recycling Technology Co., Ltd., Foshan 528244, China \\ ${ }^{2}$ Hunan Brunp EV Recycling Co., Ltd, Changsha 410600, China \\ ${ }^{3}$ Central South University, Changsha 410083, China \\ *Corresponding author: diangong306@126.com
}

Keywords: EV battery, hazardous characteristics, Li-ion batteries, complete discharged.

\begin{abstract}
Judging from the performance of lithium ion battery materials and the techniques for battery manufacturing on the market, the world will see the booming of scrap traction batteries in the next three to five years. When the time comes, the safe transportation of these batteries is going to be an imminent problem for recycling companies. By analyzing the current polocies, laws, regulations and standards, the harzards of the used traction batteries were determined. And in order to eliminate their potential risk to human bodies and the environment a pretreatment was proposed, that is, complete discharge of the batteries. As proven in the following context, the completely discharged traction batteries no longer possess the previous dangerous/hazardous characteristics, therefore, they can be treated as general goods. Lowering the recycling cost of the batteries in the meanwhile, this method provides a solution to the conundrum of used traction batteries' tranportation.
\end{abstract}

\section{Introduction}

Early in 2009, Ministry of Science \& Technology, Ministry of Finance, National Development and Reform Commission, and Ministry of Industry and Information Technology together launched the "ten cities - each one thousand energy-saving and new energy vehicles demonstration and promotion of application project" -- each year the government will provide 10 cities with financial support for the demonstration running of 1000 new energy vehicles in each city. In 2012, the State Council issued Notice No.22 [2012]- Notice of the State Council on distribution of the development plan for energy-saving and new energy vehicles industry (2012-2020). In this plan the goal is for the production and sales volume of BEV and PHEV to reach 500,000 units in 2015; by 2020, BEV and PHEV production should reach 2 million units, and the cumulative sales should be over 5 million units.

With such strong support from a series of policies inevitably comes the booming of new energy cars. As the electric vehicles rise up among the clean energy vehicles and become the mainstream of future market, traditional fuel cars will phase out. In general the service life of a traction battery is estimated to be 3-5 years [1]. The transportation cost is one of the decisive factors of the recycling cost. From our experience of working with the vehicle enterprises, the packing and transportation fee accounts for over $50 \%$ of the recycling cost when carriage of dangerous goods are used. So far most BEVs use lithium ion batteries as the power source. When the scrap of these batteries comes, their safe transportation have to be ensured before we can further reuse them. In order to concieve effective safety measures that minimize or eliminate their risk to human health and the eco-environment, the hazards of the scrap lithium ion batteries have to be studied beforehand. It is difficult, but imminent to lower the cost for packing and transportation on the premise of ensuring human safety.

By analyzing the current policies, laws, regulations and standards, the hazards of the used traction batteries were presented in this paper. And in order to eliminate their potential risk to human bodies and the environment complete discharge was proposed as a pretreatment method. Via adopting complete discharge in addition to reasonably catagorizing these batteries can be treated as general 
goods in the process of packing and transportation. In this way we can decrease the recycling cost by a great portion, which is promotive to the development of the recycling industry of used traction batteries.

\section{Hazards of the Lithium Ion Batteries}

Acronyms and Definitions. Dangerous Goods. GB 6944-2012 'Classification and code of dangerous goods' [2] clause 3.1 defines dangerous goods ( dangerous objects or dangerous items) as: chemicals with explosive, flammable, toxic, corrosive and radioacitve, etc. characteristics, special attention should be paid to those chemicals with high risk to human bodies, properties and environment during their trasportation, storage, production, distribution, usage and waste disposal .

Hazardous chemicals. In the first paragraph of chapter 1 in 'Catalogue of hazardous chemicals (2015 version)', hazardous chemicals are defined as highly toxic chemicals and other chemicals with toxic, corrosive, explosive, burning, combustion and other properties as well as hazards to human bodies, facilities and the environment.

Dangerous/Hazardous Characteristics and Classifications. Dangerous Goods. Used lithium ion batteries belong to dangerous goods, category 9 - miscellaneous, containing substance harmful to the environment.

According to the GB 12268-2012 'Name list of dangerous goods' [3] and GB 6944-2012 'Classification and code of dangerous goods' clause 4.10.1, the UN code for lithium metal battery pack(including lithium alloy battery pack) is 3090, for the lithium metal battery pack installed inside or the lithium metal battery pack(including lithium alloy battery pack) packed with the device the UN code is 3091; for lithium ion battery pack(including polymer lithium-ion battery pack) is 3480, for the lithium ion battery pack installed inside or the lithium ion battery pack(including polymer lithium-ion battery pack) packed with the device the UN code is 3481. UN 3090, UN 3091, UN 3480 and UN 3481 belong to category 9: miscellaneous, containing substance harmful to the environment.

Note: batteries or battery packs that satisfy all the following terms can be treated as general goods:

a)For lithium metal or lithium alloy battery, the lithium content is less than or equal to 1 gram, for lithium ion battery, the rated capacity is less than or equal to $20 \mathrm{Wh}$.

b)For lithium metal or lithium alloy battery pack, the lithium content is less than or equal to 2 grams, for lithium ion battery pack, the rated capacity is less than or equal to $100 \mathrm{Wh}$.

In fact, the rated capacity of used lithium ion battery or used lithium ion battery pack is usually much higher than $100 \mathrm{Wh}$. For example, the rated capacity of the cell from a german BEV is $275 \mathrm{Wh}$. Considering the fact that a battery module or pack contains more than one single cell, its rated capacity is definitely higher than $100 \mathrm{Wh}$. Therefore, lithium ion battery module or pack belongs to category 9: miscellaneous, containing substance harmful to the environment.

Hazardous Chemicals. There are two reasons why used lithium ion traction battery does not belong to hazardous chemicals:

Reason 1: It is not in the 'Catalogue of hazardous chemicals (2015 version)';

Reason 2: According to the abovec lause 1.1.2, hazardous chemicals are defined as highly toxic chemicals and other chemicals with toxic, corrosive, explosive, burning, combustion and other properties as well as hazards to human bodies, facilities and the environment. The object has to be a chemical first, which lithium ion battery isn't.

In GB/T 16483-2008 'Safety data sheet for chemical products - Content and order of sections' clause 2.1 defines chemical product as: substance or mixture. Clause 2.2 defines substance as: chemical elements or compounds in natural state or those generated from any manufacturing process, including any additive necessary for keeping it stable or any impurity during the process, excluding any seperatable solvent that neither affects the stability nor changes the composition. According to the definition, lithium ion battery dose not belong to substance or mixture given in GB/T 16483-2008, thus it is not a chemical. 


\section{Complete Discharge}

Definition of Complete Discharge.Complete discharge, is the process of diselectrifying an electrified battery. For those the external shell of which are intact, complete discharge can be achieved through physical discharge, that is, by connecting the used battery with special discharger or automated discharge system so as to the battery's voltage drops to 0 volt; for those that are too damaged to connect with the discharge device, complete discharge can still be achieved via chemical discharge, that is, putting the battery in discharge liquid, shorting the battery externally so as to the voltage drops to 0 volt.

Necessity of Complete Discharge. Requirement In Policies. In 'Technical Policy for Discarded Batteries Pollution Prevention [No.82 (2016)]' Chapter 3 stipulates that "measures of pre-discharge and independent packing etc. should be taken before transporting discarded lithium ion batteries, preventing environmental risks of explosion etc. caused by impact or short.”

Requirement In Treating Techniques. It is the first step of discharging the battery in most treatment techniques for recycling the used lithium ion batteries, which is usually done with special discharger or discharge liquid. The outbreak of explosion or burning is prevented by releasing the residual elctrical energy. Discharge of the used batteries has become one of the necessary steps for recycling.

Requirement On Special Conditions. When transporting unstable batteries( batteries that showed signs of fuming, blazing, severe deformation and abnormal temperature ect. after accidents or experimental abuse), pretreatment of discharge has to be employed to ensure the safty of the process. Discharge is currently the most effective and cheap pretreament for safe transporation.

\section{Hazardous Characteristics}

Non-Explosive. Definition of explosive. GB 6944-2012 'Classification and code of dangerous goods' defines explosive as: solids or liquids(or mixtures) that can, via chemical reactions by itself, generate gases at temperature, pressure and speed high enough to bring damage to the surroudings. GB/T 21535-2008 'Dangerous chemicals - Terms of explosives' defines explosive as: "the phenomenon of a chemical reaction or change of state where a great amount of energy is released in a very short time, creating a high temperature, releasing great quantities of gases and imposing high pressure on the surroundings. An explosive is "a solid or liquid that may react violently should it be exposed to external stimuli such as heat, pressure and impact etc., generating great quantities of gases and heat, causing a sharp rise in the surrouding pressure and an explosion, as well as damage to the surroudings; objects that won't explode wholely but can result in combusion, high-velocity projectiles and small explosion are also included."

Explosion mechanisms of lithium ion batteries. Lithium ion batteries explode due to the great quantities of heat and gases released in the chemical and electri-chemical reactions among the active materials and the electrolyte. There are mainly 3 types of explosion:

a.Explosion due to short. In the cases of short, acupuncture and impact etc., a very intense electric current is created in an extrem short span of time; huge amount of heat is generated due to over potential and ohmic ploarization [4]. The temperature is elevated by the heat and when it reaches the reaction temperature, the great amount of heat produced by cathode's decomposition results in an explosion.

b.Explosion due to overcharge. In the case of overcharge, the slip-off lithium ions from the anode react with the solvent, giving off a great amount of heat, which further promotes the reactions between the lithium metal and the solvent, the lithium-intercalated carbon and the solvent. Consequently great quantities of heat and gases from these reactions set off an explosion,

c.Explosion due to thermal impact. When the battery is heated to $100{ }^{\circ} \mathrm{C}$ or so, phase protecting film begins to decompose, the released heat further heats up the battery, promoting the reactions in the following sequence: the reaction between cathode and solvent, decomposition of the anode and 
the reaction between anode and electrolyte, releasing great quantities of heat and resulting in burning and explosion of the battery.

Non-explosive after complete discharge. Batteries after being completely discharged to $0 \mathrm{~V}$ is non-explosive. For there is no voltage difference within, there won't be electric current at short, nor will there be any heat generated. What's more, anode materials like lithium manganate, lithium iron phosphate and trenary anode materials etc. are in sub-stable state when charging and going to decompose should the temperature be elevated; whereas the batteries after complete discharge are very stable at a temperature below $650{ }^{\circ} \mathrm{C}$, there will be no gasses released by decomposition. Therefore, lithium ion batteries after complete discharge is non-explosive.

Non-Flammable. Definition of flammable solids. GB 6944-2012 'Classification and code of dangerous goods' defines flammable solid as: solids that are readily combustible, or may cause fire through friction. GB 30000.8-2013 'Rules for classification and labelling of chemicals-Part 8:Flammable solids' defines flammable solids as: Flammable solids are solids that are readily combustible, or may cause or contribute to fire through friction. Readily combustible solids are powdered, granular, or pasty substances which are dangerous if they can be easily ignited by brief contact with an ignition source, such as a burning match, and if the flame spreads rapidly.

Burning mechanisms of lithium ion battery. There are serveral possible reasons for the lithium ion batteries to burn [5]:

a.Decomposition of unstable electrode materials giving off oxygen.

b.Reaction during charging or discharging between carbon cathode and the deintercalated oxygen from anode giving off flammable gases like carbon monoxide etc..

c.Reaction when cathode and organic solvent are imcompactible between intercalated lithium into cathode and organic solvent giving off flammable gases like carbon monoxide and ethene etc..

d.Decomposition of lithium salts in electrolyte giving off oxygen on the one hand, generation of strong acid because of water penatration and the aftermath: acid reaction with carbon cathode giving off flammable gases, and corrosion of the diaphragm causing short.

e.Decomposition of organic solvent at heating or working voltage gjving off flammable gases like methane.

f.Thermal oxidation or ageing of diaphragm causing short.

g.Misuse of batteries of different capacities, reversing the ones of smaller capacities due to over discharge and as a result accumulating lithium upon the anode forming flammable and explosive substance.

Each part of the lithium ion battery is likely to cause battery burning and interlocks with each other, which means, one goes wrong, all goes wrong - ensuing chemical reaction and burning.

Non-flammable after complete discharge. The lithium ion batteries are void of electrical energy; the electrode materials within are stable and won't decompose easily; there is no self discharge within the batteries, no reaction between carbon cathode and the anode; there is no intercalated lithium into carbon cathode, eliminating the possibility of lithium reaction with organics; there is no voltage difference, nor electrical current, nor short, nor burning. Lithium ion battery, module and pack consisting of salts, metals, graphene, solution and a small amout of plastic, it can not be easily ignited by brief contact with an ignition source. Therefore, lithium ion batteries after complete discharge is non-flammable [6].

Non-Toxic, Non-Infectious and Non-Corrosive. Definitions of toxic, infectious and corrosive. GB 6944-2012 'Classification and code of dangerous goods' defines toxic as: substances that is to cause severe injuries or harmful to health or lethal if consumed or contact with the skin. HJ/T 298-2007 'Technical specifications on identification for hazardous waste' defines toxic as: "substances that is gravely harmful to health or lethal if consumed or or contact with the skin."

GB 6944-2012 'Classification and code of dangerous goods' defines infetious as: a infectious substance is one that contains known or that there is reason to believe to contain pathogens. 
GB 6944-2012 'Classification and code of dangerous goods' defines corrosive as: a corrosive substance is one that will cause severe injuries to living tissues through chemical reactions when it comes into contact or severe damage even destroy other goods or transportation vehicles.

Structure design requirements for lithium ion batteries. Batteries that pass the safety tests in GB/T 31467.3-2015 'Lithium-ion traction battery pack and system for electric vehicles-Part 3:Safety requirements and test methods' are of good performance and don't have the problems like broken shells.

JB/T 11141-2011 'General requirement for module case of lithium-ion battery' stipulates that the degrees of protection provided by cases for outdoors and airbone lithium ion battery modules shall be higher or equal to level IP55 stipulated in GB 4208-2008 'Degrees of protection provided by enclosure(IP code)' , whichi set strict restrictions on solid foreign bodies and water proof.

The cell is a basic device that transforms chemical energy into electrical energy, consisting of Anode and cathode materials, diagragm, electrolyte, shell and terminals etc.. For that the eletrolyte is volatile when in contact with air, usually welding is applied for strict sealing in the process of battery manufacturing.

Non-toxic, non-infectious, non-corrosive after complete discharge. The structure design of lithium ion battery, module or pack make sures the of palcable parts are non-toxic; void of pathogen ensures that it is non-infetious; strict sealing of the case prevents the electrode materials and electrolyte from leaking, thus it is also non-corrosive.

\section{Advise on Classification and Transportation}

At present there the types of batteries require reclycling are complicated, no matter they are the ones from normal scrap or accidental scrap or testing scrap etc., they all need to be tested and reasonably sorted by its hazardous characteristics into different risk level; proper means of packing and transportation should be employed according to the risk level.

Lithium ion batteries after complete discharge are no longer explosive, flammable, toxic, infectious or corrosive, meaning there is no risk during the transportation, these treated batteries should be categorized as one kind which needs not over protection, just like the general goods. In doing so the transportation cost is decreased while ensuring safe transportation. This pretreatment method in conclusion is scientific, economic and viable.

The lithium ion batteries after complete discharge, are safe and can be packed and trasnportaed as gerneral goods. Ttreating as dangerous goods will only increase the recycling cost, which is at odd with the released encouraging policies about new energy vehicles and harmful for the development of the recycling of used traction batteries. In the 'Technical Policy for the Recycling of Traction batteries of Electric Vehicles (2015)' Item No.4 stipulates that the recycling of traction batteries should be carried out in accordance with the principle of minimizing the resources comsuption and waste generation on the premises of technical viable, economic, safe and conducive to resources conservation and environmental protection.

\section{Summary}

Used tracting batteries do not belong to dangerous chemicals; they do, however, belong to dangerous goods, falling into the category 9: miscellaneous, containing substance harmful to the environment. After complete discharge, the risk of the batteries will be eliminated, enabling them to be packed and transported as general goods. In doing so the transportation cost is decreased while ensuring safe transportation. The procedure of this method can be readily carried out and the determination criterion is very simple; it is, in conclusion, a smart move against the transportation predicament of used lithium ion batteries. 


\section{Acknowledgement}

This research was financially supported by the National Science and Technology Support Program (No. 2014BAC03B01), National Science and Technology Support Program (No. 2015BAB0205) and Guangdong Province Collaborative Innovation and Platform Environment Construction Special Fund Project (No. 2016B090918011).

\section{References}

[1] H.J. Yu, Y.H. Xie and T.Z Zhang, Technical progress on power batteries recovery for electric vehicle, The Chinese Journal of Nonferrous Metals, 24(2014) 448-460.

[2] GB 6944-2012 'Classification and code of dangerous goods'.

[3] GB 12268-2012 'Name list of dangerous goods'.

[4] H.J. Yu, Y.H. Xie, Y.N Ou and C. D. Li, Research on storage security of waste battery for electric vehicle. Chinese Journal of Power Sources, 39(2015)745-748.

[5] H.J. Yu, Y.H. Xie, C. D. Li, Research on waste electric vehicle battery transportation security. Safety \& Environmental Engineering, 21(2014)170-173.

[6] Y.H. Xie, H.J. Yu, Y.N Ou and C. D. Li, Environmental impact assessment of recycling waste traction battery. Inorganic Chemicals Industry, 21(2014)170-173. 